\title{
Correlação entre uso da terra e feições geomorfológicas: uma proposta de análise a partir da cartografia retrospectiva
}

\section{Correlation between land use and geomorphological features: a proposal of analysis using retrospective mapping}

\author{
Felipe Augusto Scudeller Zanatta 1 \\ Cenira Maria Lupinacci ${ }^{2}$ \\ Marcos Noberto Boin ${ }^{3}$
}

\begin{abstract}
Palavras-chave:
Cartografia retrospectiva

Processos erosivos

Cobertura superficial da terra

Técnicas conservacionistas
\end{abstract}

\begin{abstract}
Resumo
Distintos estudos da ciência geomorfológica se dedicam a compreender o efeito da ação humana na dinâmica natural dos ambientes. Nessa perspectiva, o presente artigo objetiva identificar o efeito da agricultura e das técnicas conservacionistas sobre a dinâmica dos processos de vertentes e de fundos de vale em uma área rural degradada. Para tanto, como objeto de estudo foram selecionadas subbacias do ribeirão Areia Dourada, localizadas no município de Marabá Paulista (SP), nas quais se utilizaram de princípios da cartografia retrospectiva, com o mapeamento do uso e cobertura superficial da terra e das feições geomorfológicas nos anos de 1963, 1979, 1997, 2011 e 2016. Para análise, junto aos mapeamentos e registros de campo, buscou-se com o Coeficiente de Correlação de Pearson (p) avaliar conjuntamente, com dados quantificados, as alterações das formas de relevo a partir do uso da terra nos cinco anos mapeados. Como resultado, constatou-se: desenvolvimento conjunto dos processos erosivos em distintos compartimentos topográficos; sistema de retroalimentação entre os processos de vertentes e fundos de vale; a baixa eficiência dos terraços agrícolas, tanto nas áreas de cultivo, mas, sobretudo nas áreas de pasto, de modo a contribuírem com a dinâmica erosiva ao alimentar processos erosivos de subsuperfície, ao mesmo tempo que não contém os de superfície.
\end{abstract}

\section{Keywords:}

Retrospective cartography

Geomorphological features

Superficialcover

Conservation techniques

\begin{abstract}
Different studies of geomorphological science are dedicated to understanding the effect of human action on the natural dynamics of environments. Following it, this article aims to identify the effect of agriculture and conservation techniques on the dynamics of slope and bottoms of valley processes in a degraded rural area. We selected, for it, the sub-basins of Areia
\end{abstract}

\footnotetext{
${ }_{1}^{1}$ Prefeitura Municipal de São Paulo. felipeasz@hotmail.com

2 Instituto de Geociências e Ciências Exatas, UNESP, campus de Rio Claro. cenira.lupinacci@unesp.br

${ }^{3}$ Faculdade de Ciências e Tecnologia, UNESP, campus de Presidente Prudente. marnorboin@gmail.com
} 
Dourada stream, located in the city of Marabá Paulista (SP), as objects of study, in which we used the principles of retrospective mapping, with the mapping of land use and superficial surface cover and the geomorphological features of 1963, 1979, 1997, 2011 and 2016. For the analysis, along with the mappings and field records, we used the Pearson's Correlation Coefficient (p), together with quantified data, to evaluate the changes of the forms of relief from land use in the five mapped years. As a result, we verified: joint development of the erosive processes in different topographic compartments; feedback system between slope and bottoms of valley processes; the low efficiency of the agricultural terraces, both in the cultivated areas, but especially in the pasture areas, in order to contribute to the erosive dynamics by feeding erosive subsurface processes, while not containing the surface ones.

\section{INTRODUÇÃO}

Diversos estudos da geomorfologia buscam identificar o efeito da ação humana sobre os sistemas naturais, construindo um ramo dedicado a interpretar as interferências antrópicas como agente geomorfológico, denominado antropogeomorfologia (NIR, 1983). Para essa análise, a cartografia geomorfológica retrospectiva representa um recurso que possibilita o acompanhamento e identificação das alterações nas formas de relevo em tempo histórico. A partir dessa técnica, distintos estudos apontaram os efeitos das ações humanas em ambientes diversos, como: alterações na dinâmica fluvial dos rios que atravessam a cidade de São Paulo (LUZ; RODRIGUES, 2015); os efeitos da mineração (PASCHOAL, 2014); a influência de barragens sobre a morfohidrografia (SIMON, 2010); do represamento do Rio Paraná e as consequentes mudanças no nível de base regional e reativação da rede de drenagem (QUARESMA, 2012); do pastoreio excessivo contribuindo na formação de fenômenos erosivos lineares em terrenos pouco sujeitos a tais processos (ZANATTA; LUPINACCI; BOIN, 2017a), entre outros.

Dos processos que atuam sobre os solos, alterações significativas ocorrem apenas com a substituição da flora e fauna nativa. Nas áreas agrícolas e urbanas, as novas coberturas inserem-se em um ambiente com uma dinâmica predeterminada por condicionantes físicos naturais, que passam a agir sobre um plano artificial, em que a lógica, por muito distante da dinâmica natural, determina-se por relações econômicas, políticas e sociais.
A exemplo das mudanças nos processos que atuam nos solos, no estado de São Paulo, Bertoni e Lombardi Neto (1990), constataram que, sob matas nativas, a perda de solo ocorreu na ordem de 0,004 t/ha/ano. Nas áreas de pasto, o volume foi 100 vezes superior, com 0,4 t/ha/ano, enquanto em cultivo de cana-de-açúcar, 3.100 vezes maior, com 12,4 t/ha/ano. Considerando as características do solo, os autores identificaram que os arenosos apresentam maior perda de solo em t/ha.

Dentre os efeitos que ocorrem nos solos, que contribuem para erosão, Wendling et al. (2005) constataram significativa redução na concentração de carbono orgânico e da estabildiade dos agregados nos solos sob cultivo agrícola, quando comparado aos valores anteriores ao desmatamento. Para Kiehel (1979, apud WENDLING et al, 2005) a formação de agregados está relacionada à ação mecânica das raízes e excreção de substâncias com ação cimentante e que, quanto mais exposta a superfície do solo, maior a redução da estabilidade dos agregados, favorecendo processos de selagem em sua superfície, induzindo ao escoamento superficial e à erosão.

Charlton (2008) alerta que a retirada da vegetação tem como consequência o aumento da proporção de água da chuva que escoa superficialmente, acelerando processos erosivos. Nessas condições, maiores volumes de sedimentos e água chegam nos canais fluviais e proporcionam alterações nos fundos de vale. Abdon (2004) constatou que o pastoreio excessivo, o manejo inadequado do solo e o uso indevido de certas áreas, proporcionaram o desenvolvimento de ravinas e voçorocas, aumentando a quantidade de água e de sedimentos que chegam ao canal principal da 
bacia. Tal efeito resultou no assoreamento excessivo do rio Taquari e em alterações do seu curso, de modo a transbordar e inundar extensas áreas de campo, utilizadas anteriormente para pecuária extensiva.

Nesse contexto, objetiva-se neste artigo identificar em área rural degradada o efeito da ação antrópica sobre os processos erosivos e fundos de vale ao longo de 53 anos, em um conjunto de subbacias do ribeirão Areia Dourada (Figura 1), localizadas no município de Marabá Paulista, no extremo Oeste Paulista.

Figura 1 - Localização da área estudada

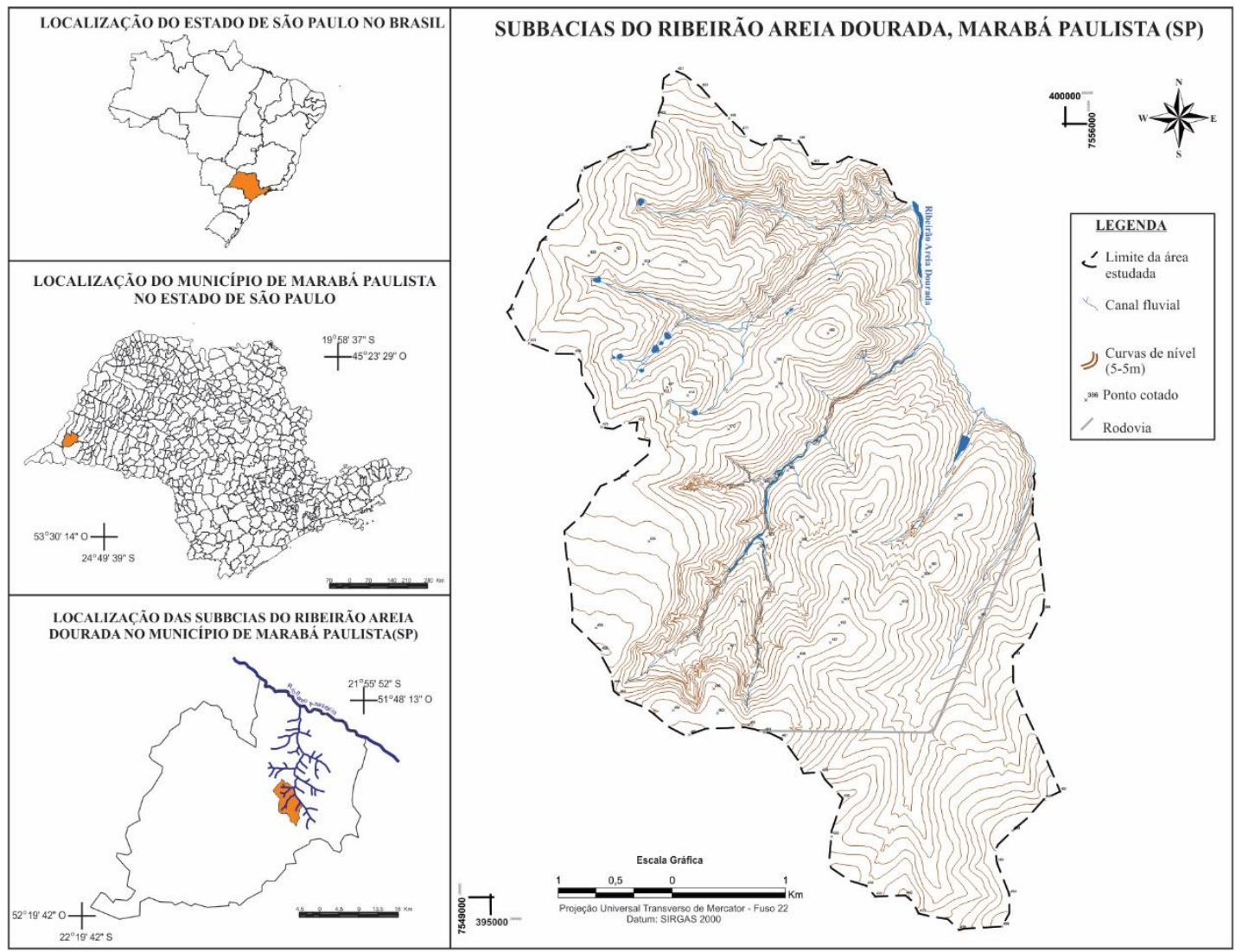

Fonte: Elaboração dos autores, 2019.

Para atingir este objetivo foram utilizados princípios da cartografia retrospectiva no levantamento de dados geomorfológicos e do uso da terra, assim como técnicas estatísticas de análise das informações levantadas, de maneira a identificar as mudanças e criar hipóteses a respeito da influência da ação humana na intensidade e dinâmica dos processos geomorfológico.

\section{MATERIAIS E TÉCNICAS CARTOGRÁFICAS}

Como base para os mapeamentos geomorfológicos e de uso e cobertura da terra, utilizaram-se os dados de topografia das cartas do Instituto Geográfico e Cartográfico do Estado de SãoPaulo (IGC) do ano 2000, em escala 1:10.000, folhas 057/019, 057/20 e 058/20. Destas cartas, foram vetorizadas as curvas de nível, com equidistância de cinco metros, os pontos cotados e adicionados os respectivos valoresaltimétricos, utilizando, também. desta escala como padrão na produção cartográfica.

Para os mapeamentos de uso e cobertura superficial da terra, assim como geomorfológicos, nos cinco anos mapeados, foram utilizadas distintas fontes e diferentes técnicas de fotointerpretação, que obedeceram as características dos produtos de sensoriamento remoto conforme descrito na Tabela 1. 
Tabela 1. Fotografias utilizadas para os mapeamentos das feições geomorfológicas e do uso e cobertura superficial da terra.

\begin{tabular}{|c|c|c|c|c|}
\hline Fonte & Ano & Escala/Resolução & $\begin{array}{l}\text { Fotografias no } \\
\text { catálogo }\end{array}$ & $\begin{array}{ll}\text { Tipo } & \text { de } \\
\text { mapeamento } & \\
\text { realizado } & \end{array}$ \\
\hline Estado de São Paulo & 1963 & 1: 25.000 & $\begin{array}{l}\text { FX91A-2857 e } 2858 ; \\
\text { FX92-2871 e } 2873 ; \text { e } \\
\text { FX93-2921 e } 2922 .\end{array}$ & $\begin{array}{l}\text { Fotointerpretação } \\
\text { em estereoscopia } \\
\text { digital. }\end{array}$ \\
\hline Terrafoto S.A. & 1979 & 1: 25.000 & $\begin{array}{l}\text { FX91A-2857 e } 2858 ; \\
\text { FX92-2871 e } 2873 ; \text { e } \\
\text { FX93-2921 e } 2922\end{array}$ & $\begin{array}{l}\text { Fotointerpretação } \\
\text { em estereoscopia } \\
\text { digital. }\end{array}$ \\
\hline $\begin{array}{l}\text { Aerolevantamento } \\
\text { Presidente } \\
\text { Venceslau e áreas } \\
\text { correlatas }\end{array}$ & 1997 & $1: 35.000$ & $\begin{array}{l}\text { 07/5884; } 07 / 5885 \text { e } \\
07 / 8856 .\end{array}$ & $\begin{array}{l}\text { Fotointerpretação } \\
\text { em estereoscopia } \\
\text { digital. }\end{array}$ \\
\hline $\begin{array}{l}\text { Empresa de } \\
\text { Planejamento } \\
\text { Metropolitano S.A. }\end{array}$ & 2010 & Resolução $0,45 \mathrm{~m}$ & $\begin{array}{l}\text { SF_22_YB_I_2_ } \\
\text { e } \quad \text { SE; } \\
\text { SF_22_YB_II_1_NO } \\
\text { e SO. }\end{array}$ & $\begin{array}{l}\text { Fotointerpretação e } \\
\text { reambulação dos } \\
\text { dados em campo. }\end{array}$ \\
\hline $\begin{array}{l}\text { Google Earth - } \\
\text { satélite Quickbird }\end{array}$ & 2013 & Resolução 0,6m & Sem informação. & $\begin{array}{l}\text { Fotointerpretação e } \\
\text { reambulação dos } \\
\text { dados em campo. }\end{array}$ \\
\hline
\end{tabular}

Fonte: Elaboração dos autores, 2019.

Com os materiais dos anos de 1963, 1979 e 1997, aerolevantamentos em faixas, foi possível trabalhar em esteresocopia digital, adquirindo a tridimensionalidade das feições. Para tanto, seguiram-se as orientações de Souza e Oliveira (2012) para obtenção dos anaglifos no software StereoPhoto Maker. Já para o material de 2010 e de 2013, tratando-se de ortofotos e imagem de satélite, pela impossibilidade de obtenção da tridimensionalidade pelo método mencionado, os levantamentos foram reambulados em campo.

Cabe destacar, que embora haja discordância entre as escalas dos aerolevantamentos e a utilizada neste estudo, realizou-se a fotointerpretação com o máximo de zoom e detalhe possível, considerando-se, portanto, que as feições levantadas são passiveis de serem cartografadas e trabalhadas na escala da base cartográfica.

As feições geomorfológicas foram mapeadas de acordo com sua natureza espacial, adotando o tipo geométrico (ponto, linha, polígono) que melhor se adaptava as suas características. A partir disso, os dados foram quantificados em área (hectare), quantidade (número) ou extensão $(\mathrm{km})$ de acordo com o procedimento de mapeamento adotado. (Tabela 2); àquelas calculadas em hectare foram transformadas em porcentagem da área em relação à área todal das subbacias 
Tabela 2. Características das feições geomorfológicas e tipos de tratamento dos dados

\begin{tabular}{|c|c|c|c|}
\hline $\begin{array}{l}\text { Natureza } \\
\text { espacial }\end{array}$ & Feição & Tipo geométrico & $\begin{array}{ll}\text { Cáculo } & \text { de } \\
\text { dimensão } & \end{array}$ \\
\hline \multirow[t]{4}{*}{ Área } & $\begin{array}{l}\text { Marcas que indicam erosão } \\
\text { laminar }\end{array}$ & \multirow[t]{4}{*}{ Polígono } & \multirow[t]{4}{*}{ Hectare (ha) } \\
\hline & $\begin{array}{l}\text { Área de terraço e planície } \\
\text { fluvial }\end{array}$ & & \\
\hline & Terraço agrícola & & \\
\hline & Açude & & \\
\hline \multirow[t]{4}{*}{ Quantidade } & Sulco & \multirow[t]{4}{*}{ Linha } & \multirow{4}{*}{$\begin{array}{l}\text { Número total de } \\
\text { feições } \\
\text { mapeadas }\end{array}$} \\
\hline & Ravina & & \\
\hline & Feições erosivas bliteradas & & \\
\hline & Bacias de contenção & & \\
\hline \multirow[t]{5}{*}{ Comprimento } & Canal fluvial com fundo plano & \multirow[t]{5}{*}{ Linha } & \multirow{5}{*}{$\begin{array}{l}\text { Quilômetros } \\
(\mathrm{Km}) \text { totais de } \\
\text { sua extensão }\end{array}$} \\
\hline & $\begin{array}{l}\text { Canal fluvial com fundo em } \\
\text { "V" }\end{array}$ & & \\
\hline & $\begin{array}{l}\text { Canal fluvial com solapamento } \\
\text { das margens }\end{array}$ & & \\
\hline & Rupturastopográfica abrupta & & \\
\hline & $\begin{array}{l}\text { Ruptura topográfica abrupta } \\
\text { com afloramento de água }\end{array}$ & & \\
\hline
\end{tabular}

Fonte: Elaboração dos autores, 2019.

$\mathrm{Na}$ escolha das feições a serem mapeadas e na símbologia a ser utilizada nas cartas geomorfológicas, foram seguidos os princípios do sistema de mapeamento francês (TRICART, 1965) e do sistema apresentado pelo Internacional Institute for Aerial Survey and Earth Science (ITC), proposto por Verstappen e Zuidam (1975), uma vez que se buscaram nessas metodologias, procedimentos que possibilitassem reconhecer os processos morfogenéticos dominantes. Foram realizadas adaptações às metodologias para atender ao universo particular estudado, criando-se novos símbolos para feições típicas da área, que não existiam nas propostas originais; e atribuindose cores diferenciadas a fim de destacar as feições erosivas, mapeadas em vermelho, e o modelado antrópico, mapeado em cinza. (Figura 2).

Para diferenciar as feições erosivas lineares, seguindo a revisão apresentada por Zanatta, Lupinacci e Boin (2017b), consideraram-se sulco como pequenas incisões verticais passíveis de correção porprocedimentos simples de preparo do solo(LAL,1990; SALOMÃO, 2012; SOIL SURVEY STUFF, 1993); ravinas como incisões mais profundas, com formação de fundo com paredes laterais (FOOKES, 2007; KARMAN, 2008); e voçorocas quando a erosão linear atinge e expõe o lençol freático (DAEE; IPT, 1989; FOOKES, 2007; SALOMÃO, 2012). 
Figura 2 - Símbolos utilizados nas cartas geomorfológicas.

\begin{tabular}{|c|c|c|c|c|c|}
\hline Elementos & \multicolumn{3}{|c|}{ Denominação } & Simbolo & Fonte \\
\hline \multirow{12}{*}{ Interfluvio } & \multirow{3}{*}{$\begin{array}{l}\text { Forma da } \\
\text { vertente }\end{array}$} & \multicolumn{2}{|l|}{ Convexa } & $\theta$ & $\begin{array}{l}\text { Verstappen e Zuidam } \\
\text { (1975) }\end{array}$ \\
\hline & & \multicolumn{2}{|l|}{ Côncava } & $\stackrel{b}{\Rightarrow}$ & $\begin{array}{l}\text { Verstappen e Zuidam } \\
\text { (1975) }\end{array}$ \\
\hline & & \multicolumn{2}{|l|}{ Retilínea } & & $\begin{array}{l}\text { Verstappen e Zuidam } \\
\text { (1975) }\end{array}$ \\
\hline & \multicolumn{3}{|c|}{ Linha de cumeada suave } & & Tricart (1965) \\
\hline & \multicolumn{3}{|l|}{ Colo topográfico } & & Tricart (1965) \\
\hline & \multirow{5}{*}{$\begin{array}{l}\text { Feições de origem } \\
\text { denudativa }\end{array}$} & \multirow{4}{*}{ Hidrica } & Laminar & & $\begin{array}{l}\text { Adaptaçăo de Verstappen } \\
\text { e Zuidam (1975) }\end{array}$ \\
\hline & & & Sulco & & Tricart (1965) \\
\hline & & & Ravina & & Tricart (1965) \\
\hline & & & Voçoroca & & Tricart (1965) \\
\hline & & Gravitacional & Terracetes & $2_{2}$ & $\begin{array}{l}\text { Verstappen e Zuidam } \\
\text { (1975) }\end{array}$ \\
\hline & \multirow[b]{2}{*}{ Topografia } & \multicolumn{2}{|c|}{$\begin{array}{l}\text { Curvas de nivel com } \\
\text { equidistância de } 5 \mathrm{~m}\end{array}$} & & Convenção cartográfica \\
\hline & & Ponto cotado & & $x^{426}$ & Convenção cartográfica \\
\hline \multirow{10}{*}{$\begin{array}{l}\text { Ação das águas } \\
\text { correntes }\end{array}$} & \multirow{3}{*}{$\begin{array}{l}\text { Feições de } \\
\text { drenagem }\end{array}$} & \multicolumn{2}{|l|}{ Canal fluvial } & & Tricart (1965) \\
\hline & & \multicolumn{2}{|l|}{ Canal pluvial } & & Tricart (1965) \\
\hline & & \multicolumn{2}{|l|}{ Solapamento } & AANA & Dibieso (2013) \\
\hline & $\begin{array}{l}\text { Forma de } \\
\text { acumulação }\end{array}$ & \multicolumn{2}{|c|}{ Planície e terraço fluvial } & $\bullet$ & Tricart (1965) \\
\hline & \multirow{6}{*}{$\begin{array}{l}\text { Modelado } \\
\text { de entalhe }\end{array}$} & \multirow{2}{*}{$\begin{array}{l}\text { Fundo de } \\
\text { vale }\end{array}$} & Plano & $x$ & Tricart (1965) \\
\hline & & & Em "V" & & Tricart (1965) \\
\hline & & \multirow{4}{*}{$\begin{array}{l}\text { Ruptura } \\
\text { topográfica }\end{array}$} & Suave & & Tricart (1965) \\
\hline & & & $\begin{array}{l}\text { Suave com } \\
\text { afloramento de água }\end{array}$ & & $\begin{array}{l}\text { Adaptaçåo de } \\
\text { Tricart (1965) }\end{array}$ \\
\hline & & & Abrupta & & Tricart (1965) \\
\hline & & & $\begin{array}{l}\text { Abrupta com } \\
\text { afloramento de água }\end{array}$ & & $\begin{array}{l}\text { Adaptação de } \\
\text { Tricart (1965) }\end{array}$ \\
\hline \multirow{7}{*}{$\begin{array}{l}\text { Modelado } \\
\text { antrópico }\end{array}$} & \multicolumn{3}{|l|}{ Terraços agrícolas } & & $\begin{array}{l}\text { Adaptação de Verstappen } \\
\text { e Zuidam (1975) }\end{array}$ \\
\hline & \multicolumn{3}{|l|}{ Bacias de contenção } & & $\begin{array}{l}\text { Zanatta, Cunha e } \\
\text { Boin (2014) }\end{array}$ \\
\hline & \multicolumn{3}{|l|}{ Obliteração } & & $\begin{array}{l}\text { Zanatta, Cunha e } \\
\text { Boin (2014) }\end{array}$ \\
\hline & \multicolumn{3}{|c|}{ Canal de origem antrópica } & $x$ & Simon (2010) \\
\hline & \multicolumn{3}{|l|}{ Açudes } & & Convençăo cartográfica \\
\hline & \multicolumn{3}{|l|}{ Rodovia } & & Convenção cartográfica \\
\hline & \multicolumn{3}{|l|}{ Estrada } & & Convençăo cartográfica \\
\hline
\end{tabular}

Fonte: Elaboração dos autores, 2019. 
Convém esclarecer que os tipos de fundo de vale foram passíveis de serem mapeados a partir da fotointerpretação e da análise das ortofotos e imagens orbitais, $o$ que se deve as especificidades da dinâmica erosiva e deposicional da área estudada. Assim, em alguns setores os fundos de vale planos, devido ao excesso de sedimentos, foram nitidamente identificados, contudo, os limites da escala, impossibilitaram a delimitação das áreas de planicie fluvial, sendo tal fato mapeado a partir do uso de simbologia sugerida por Tricart (1965). Ainda, em certos setores, a dinâmica erosiva intensa presente nos cursos fluviais tornaram possível observar o entalhamento significativo dos fundos de vale, por meio da presença de margens íngremes. Essa dinâmica excepcional do sistema fluvial permitiu que, depois de mapeados os tipos de fundo de vale com os símbolos propostos (Figura 3), esses fossem quantificados linearmente, em $\mathrm{km}$.

Figura 3 - Identificação das feições fluviais em campo e fotografias.

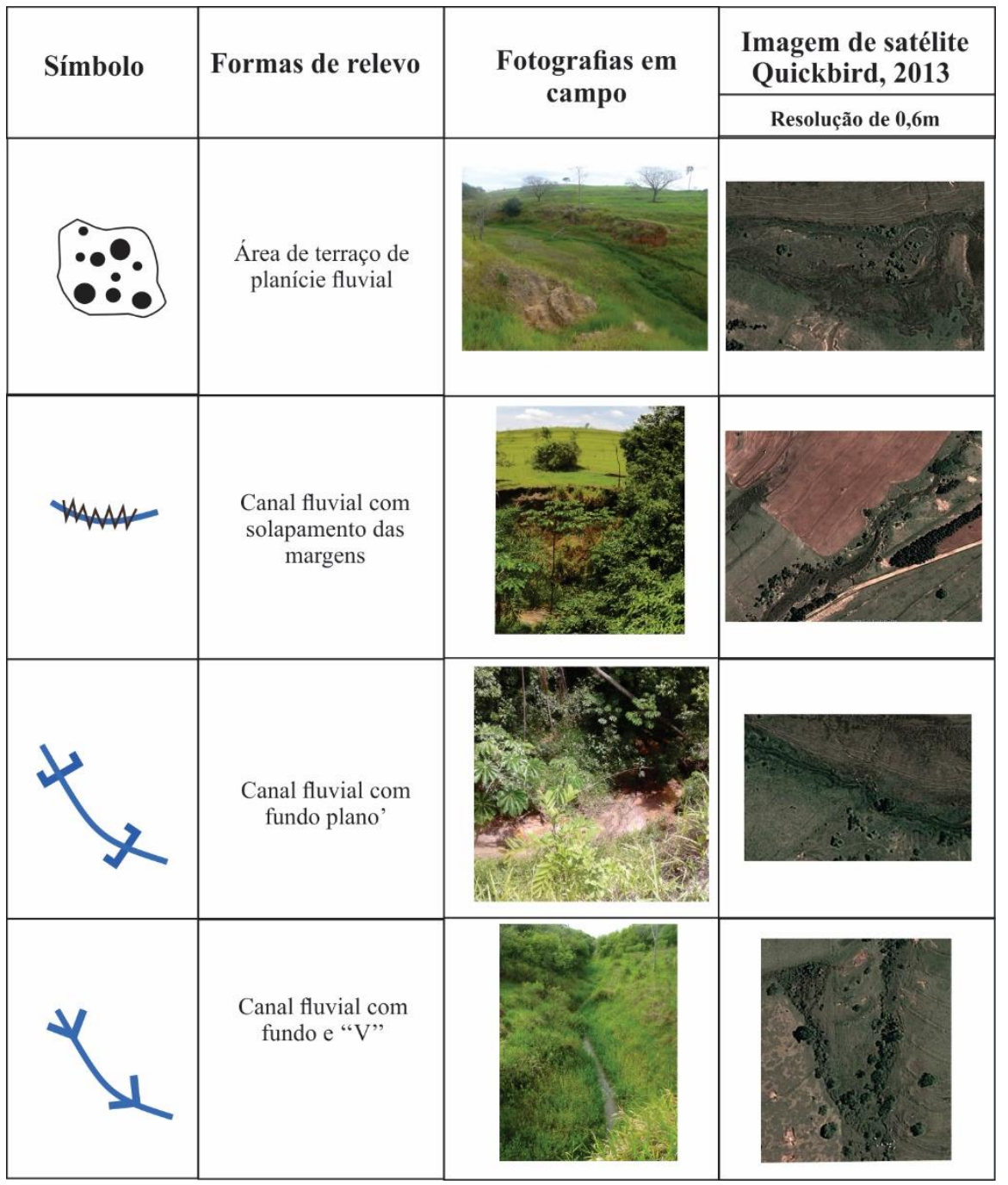

Fonte: Elaboração dos autores, 2019.

Para o uso e cobertura superficial da terra seguiram-se os procedimentos e nomenclaturas estabelecidos pelo Instituto Brasileiro de Geografia e Estatística (IBGE, 2006), identificando as áreas de: Floresta Estacional Semidecidual; reflorestamento; vegetação de área úmida; silvicultura; lavoura temporária; pasto; e pasto sujo. Como nesta metodologia, as coberturas superficiais tem dimensão espacial de área ocupada, estes dados foram quantificados a partir de sua porcentagem em relação ao total da área estudada.

Com as informações dos mapeamentos de uso e cobertura superficial da terra e geomorfológicas quantificadas de acordo com sua dimensão espacial, no programa Excel ${ }^{\circledR}$ aplicou-se o Coeficiente de Correlação de Pearson $(p)$, com objetivo de avaliar a 
intensidade de correlação nas mudanças da área ocupadas pelas classes temáticas de uso e cobertura superficial da terra e das feições geomorfológicas ao longo de cinquenta e três anos que perfazem o período entre o primeiro mapeamento de 1963 ao último em 2016. Como resultado, os valores foram marcados com tons que variam de acordo com a intensidade da correlação: nula, quando igual a 0 ; fraca, quando entre $0,1 \vdash 0,2$; média, quando entre $0,3 \vdash 0,5$; forte, quando entre $0,6+0,8$; muito forte, quando igual a 0,9; e perfeita, quando igual a 1,00), sendo em tons de verde para as positivas, referente ao crescimento propocional das feições, vermelho para as negativas, referente ao crescimento inversamente proporcional das feições, e branco para as nulas. A classificação dos intervalos partiu de adaptações daqueles apresentados por Figueiredo Filho e Silva Junior (2009).

O resultado da correlação supramencionada foi analisado junto aos mapeamentos, fotografias de campo e de outros estudos desenvolvidos na bacia do rio Santo Anastácio, de modo a comparar e explicar as informações da correlação e levantar hipóteses sobre a dinâmica dos processos atuantes em uma perspectiva histórica.

\section{RESULTADOS E DISCUSSÕES}

A ocupação de Marabá Paulista teve início pela bacia do ribeirão Areia Dourada, com a formação do povoado de Areira Dourada em medaos da década de 30, por colonos nordestino no cultivo de algodão (PREFEITURA DE MARABÁ PAULISTA, 2019).

Da formação do povoado até o primeiro ano mapeado, 1963, um período de aproximadamente três décadas, constatou-se na área estudada uma redução aproximada de 90\% da cobertura florestal nativa, de maneira a identificá-la em 9,89\% dos 4.623 ha que perfazem as subbacias (Figura 4).

Figura 4 - Floresta estacional semidecidual nas subbacias do ribeirão Areia Dourada, Marabá Paulista (SP), nos anos de 1963, 1979, 1997, 2010 e 2016.

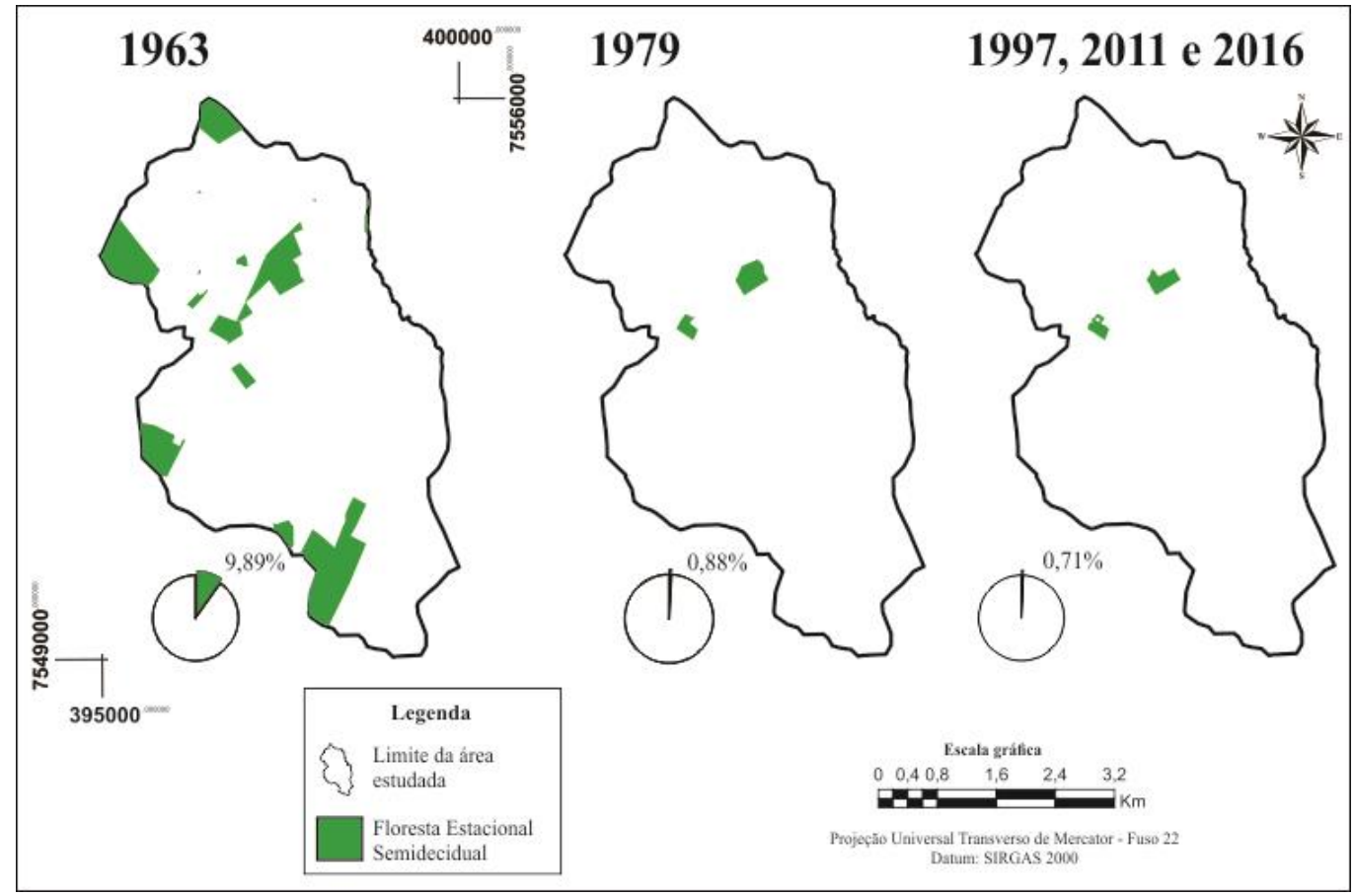

Fonte: Elaboração dos autores, 2019.

Em 1963, as coberturas superficiais que substituíram a Floresta Estacional Semidecidual dividiram-se entre lavouras temporárias $(46,62 \%)$, pasto $(23,41 \%)$ e pasto sujo $(18,47 \%)$. No período seguinte, 1979 , a área de lavoura temporária diminuiu para 3,63\%, com predomínio de pasto $(69,09 \%)$ e pasto sujo (24,84\%). Em 1997, o pasto passou ocupar $94,78 \%$ de toda área estudada (Quadro 1) 
Quadro 1. Uso e cobertura superficial da terra (\% de área ocupada) nos anos de 1963, 1979, 1997,

\begin{tabular}{lrrrrr}
\multicolumn{7}{c}{2010 e 2016} \\
\hline Uso e cobertura superficial da terra & $\mathbf{1 9 6 3}$ & $\mathbf{1 9 7 9}$ & $\mathbf{1 9 9 7}$ & $\mathbf{2 0 1 0}$ & $\mathbf{2 0 1 6}$ \\
Floresta Estacional Semidecidual & 9,89 & 0,88 & 0,71 & 0,72 & 0,70 \\
Reflorestamento & 0,00 & 0,00 & 0,70 & 1,23 & 1,20 \\
Vegetação de área úmida & 0,70 & 0,60 & 0,94 & 1,61 & 1,57 \\
Lavoura temporária & 46,62 & 3,63 & 0,80 & 18,32 & 13,45 \\
Silvicultura & 0,91 & 0,96 & 0,08 & 0,11 & 4,24 \\
Pasto & 23,41 & 69,09 & 94,78 & 72,92 & 74,30 \\
Pasto sujo & 18,47 & 24,84 & 1,99 & 5,09 & 4,54 \\
\hline
\end{tabular}

Fonte: Elaboração dos autores, 2019

Essas novas coberturas superficiais resultaram em efeitos sobre o funcionamento da paisagem diferente daqueles proporcionados pela cobertura florestal nativa. Nas áreas

recobertas por pastagens, processos como a erosão linear passaram a se desenvolver com maior frequência (Figura 5).

Figura 5 - Desmatamento e desenvolvimento de feições erosivas em área de pasto. Setor N das subbacias do ribeirão Areia Dourada, Marabá Paulista (SP).

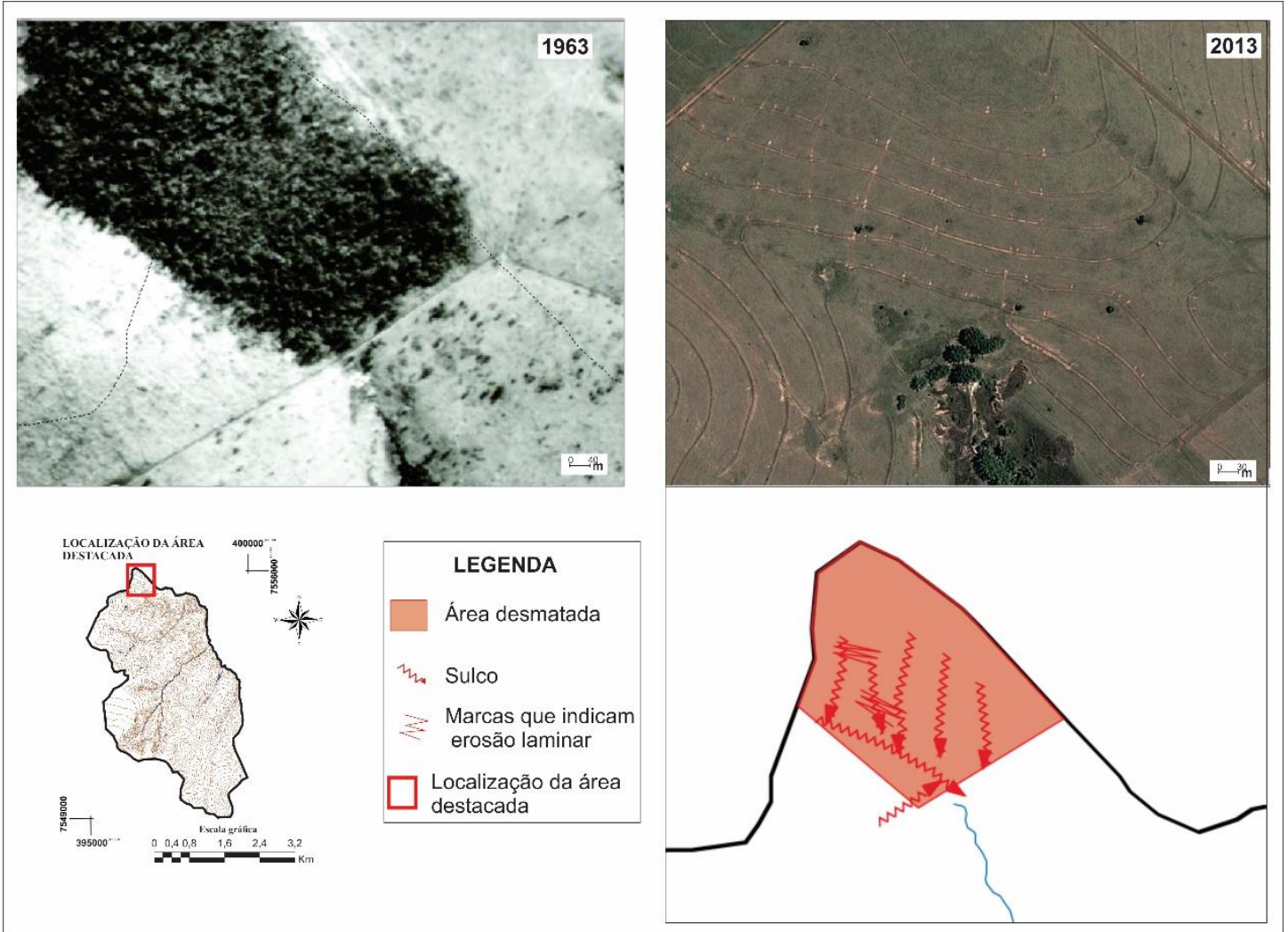

Fonte: Elaboração dos autores, 2019.

$\mathrm{Na}$ área de pasto que substitui a vegetação nativa, representada na figura 6 , registra-se o surgimento de sete feições erosivas lineares em sulco, consequente dos caminhos preferenciais pelos quais as águas pluviais se concentram em direção ao canal fluvial, erodindo a camada superficial do solo. Este fenômeno tem forte influência do pisoteio excessivo do gado, que cria as condições favoráveis para a canalização das águas pluviais.

Rodrigues et al. (2006) esclarecem que esse avanço das pastagens entre as décadas de 1970 e 1990 ocorreu também em boa parte da região do Pontal do Paranapanema, como resultado do empobrecimento do solo pelo uso intenso e erosão, que aumentou o custo de cultivo e tornou 
a agricultura inviável para os pequenos agricultores. Nessas condições, desprovidos de alternativas, esses agricultores venderam suas terras para grandes pecuaristas, os quais, de acordo com Francisco (2011), em um ambiente tomado pela erosão, introduziram na região práticas conservacionistas, com a construção de terraços agrícolas.

Posteriormente, no ano de 2011, a área de pasto foi reduzida, aumentando o cultivo da cana-de-açúcar, com o avanço das empresas sucroalcooleiras na região por arrendamento de terras. Essa lavoura temporária passou ocupar $18,23 \%$ dos terrenos em 2011, diminuindo para
13,43\% em 2016, devido ao término dos contratos de arrendamento, segundo relatos obtidos em campo, com retomada das atividades de pastagem e silvicultura.

As coberturas que substituíram a Floresta Estacional Semidecidual ao longo dos cinco anos proporcionaram expressivo e crescente aumento das formas erosivas em número (sulcos e ravinas) e área atingida (marcas que indicam erosão laminar e voçoroca) nos 53 anos analisados, mesmo quando acompanhadas de técnicas conservacionistas a partir de 1979, as quais não atenuaram a ação erosiva na área nos anos seguintes a seu emprego (Figura 6).

Figura 6 - Feições erosivas e técnicas conservacionistas e de contenção dos processos erosivos nos anos de 1963, 1979, 1997, 2011 e 2016.

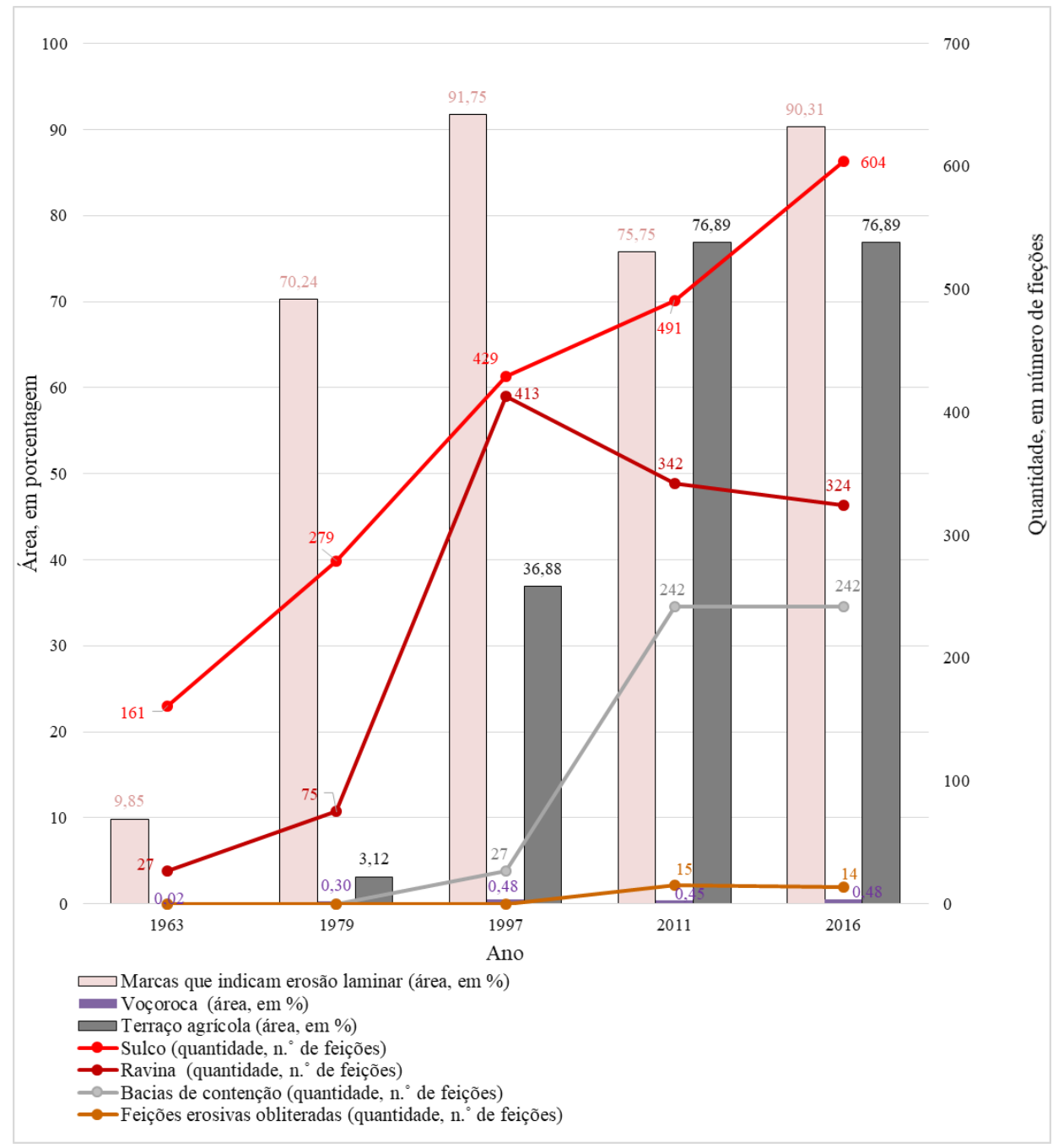

Fonte: Elaboração dos autores, 2019.

Stein, Ponçano e Saad (2003) constataram na bacia do rio Santo Anastácio essa mesma relação entre as técnicas conservacionistas e os processos erosivos. De acordo com os autores, a maior infiltração de água proporcionada pelos terraços agrícolas aumenta as recargas do lençol freático, anteriormente existentes quando sob as matas nativas. Tais recargas do lençol, em área da Formação Adamantina, proporcionam em afloramentos de água nas vertentes, com fluxo direcionado para terrenos já fragilizados e pouco protegidos pelo uso continuo e intenso das 
terras, o que desencadeia o desenvolvimento dos fenômenos erosivos.

As informações obtidas também demonstram o crescimento proporcionas das formas erosivas junto ao maior uso de terraços agrícolas na área estudada, assim como em relação à extensão dos afloramentos de água que ocorrem nas rupturas topográficas abruptas, refletindo nas alterações significaivas que ocorreram nos fundos de vale, sobretudo a partir de 1997, onde o uso dos terraçosa agrícolas tornou-se padrão das áreas cultivadas (Figura 7).

Figura 7 - Terraços agrícolas, afloramentos de água e feições vinculadas aos cursos fluviais.

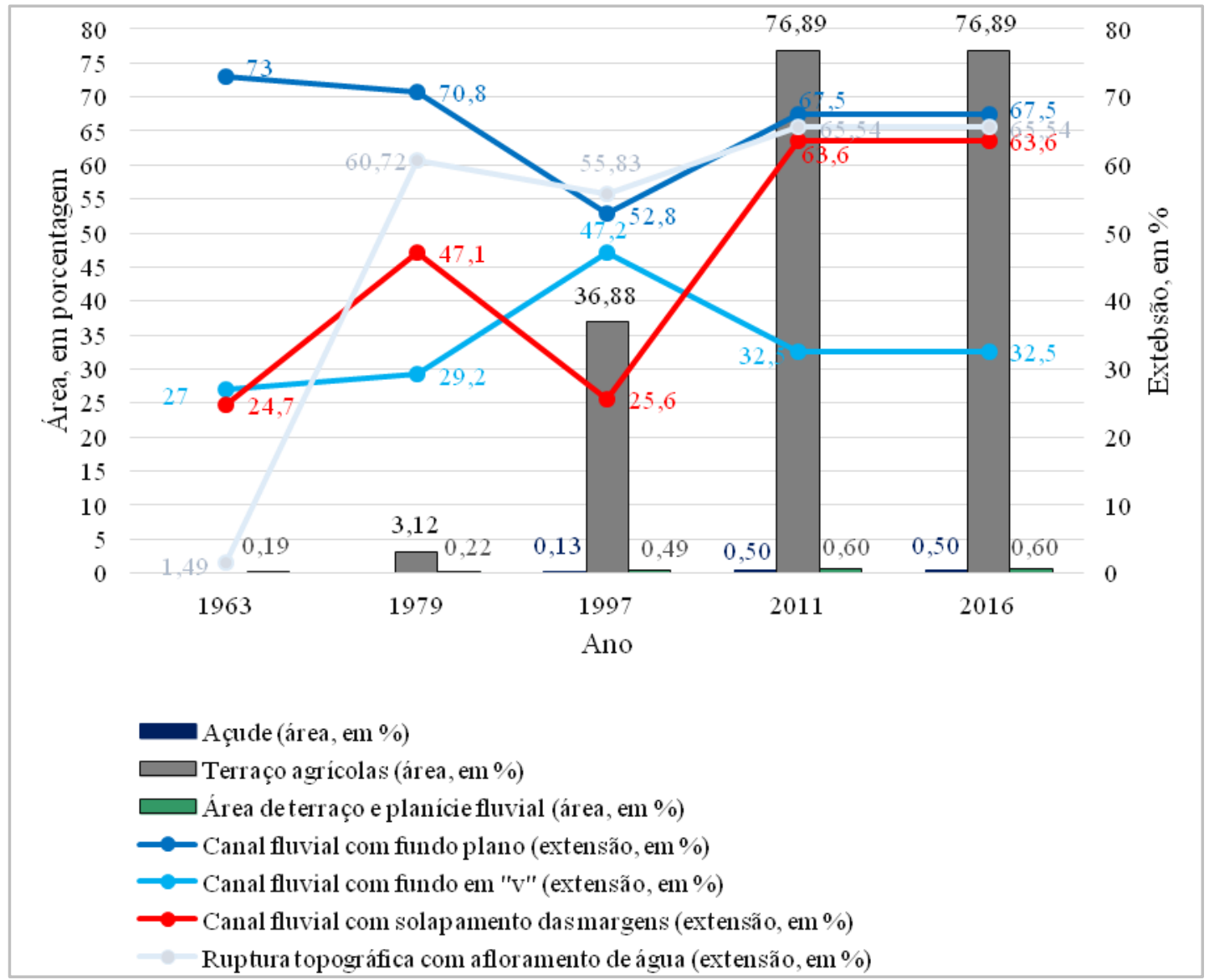

Fonte: Elaboração dos autores, 2019.

Em 1997, comparado aos anos anteriroes (1963 e 1979), reduziram-se os canais com fundo de vale plano, concomitante ao aumento das áreas de terraços e planície fluvial, devido ao assoreamento dos canais. Em outros setores, houve aumento dos fundos de vale em "v", indicando dinamização da incisão fluvial, provavelmente provocada pelo aumento dos afloramentos de água nas rupturas topográficas, que passaram a alimentar e desenvolver novos canais fluviais nas concavidades.

Em 2011 ocorreu redução dos fundos de vale em "v" e aumento dos canais com fundo plano e da área de terraço e planície fluvial (Figura 7), indicativo do constante assoreamento dos cursos fluviais pela intensa atividade erosiva nas vertentes (Figura 6). Em 2011, 63,6\% dos canais fluviais encontraram-se com solapamento das margens, devido ao aumento na quantidade de água e sedimentos vindos das vertentes.

De 2011 para 2016, no intervalo de cinco anos, não se constatou alterações das feições fluviais. Essa constatação potencialmente está relacionada ao curto período de tempo entre os anos avaliados, que não permitem verificar significativas alterações no fundo de vale, considerando o aumento dos processos nas vertentes.

Quando avaliada a correlação entre os dados geomorfológicos e de uso da terra, confirma-se a ineficiência das técnicas conservacionistas em conter os processos erosivos, a influência das pastagens na ativação desses processos e o crescimento proporcional entre as formas erosivas (Tabela 3). 
Tabela 3. Coeficiente de Correlação de Pearson (CCP) entre as variáveis uso da terra e feições geomorfológicas ao longo dos anos de 1963, 1979 e 1997, 2011 e 2016.

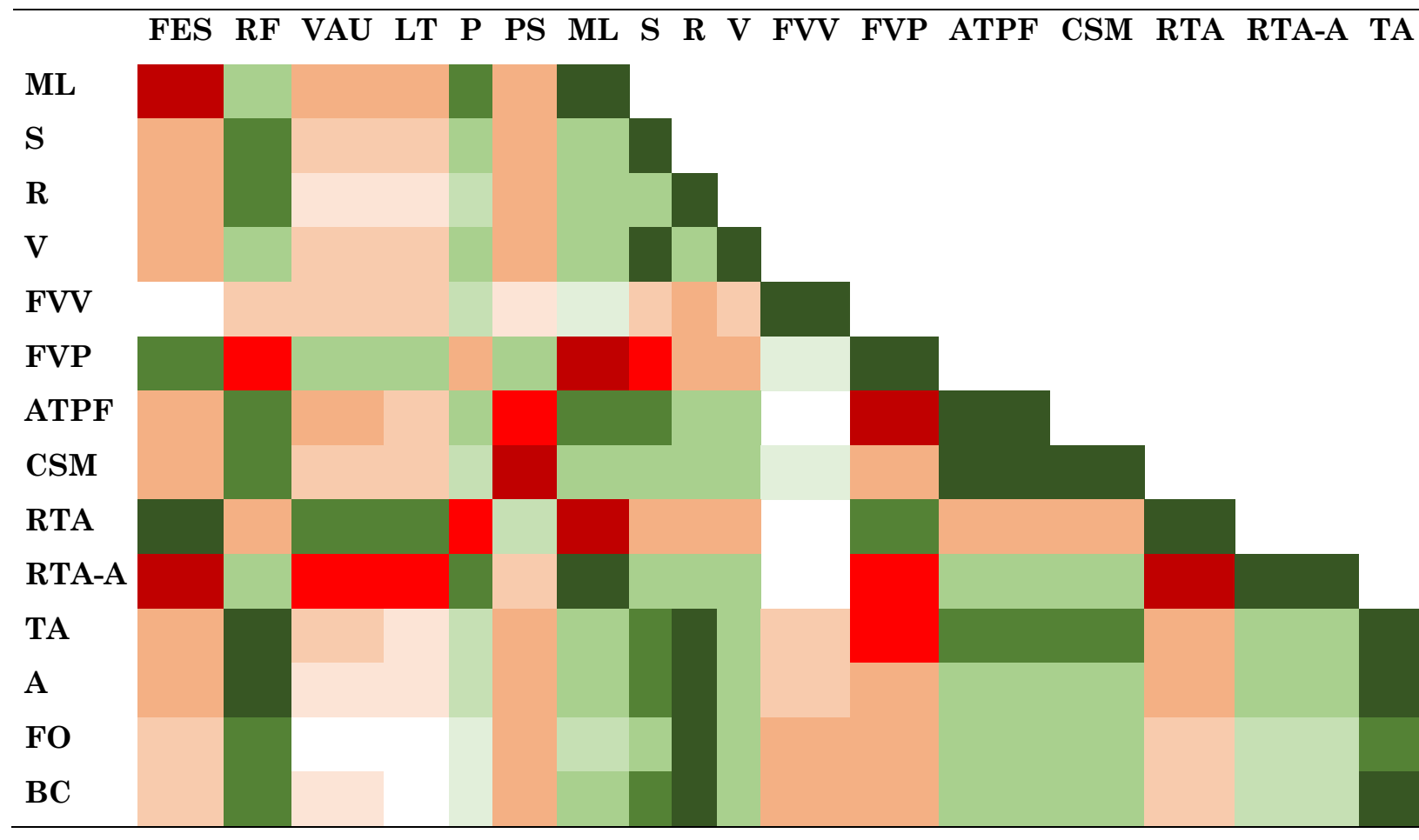

\begin{tabular}{|l|l|l|}
\hline \multicolumn{3}{|c|}{ Legenda } \\
\hline $\begin{array}{l}\text { Intensidade da } \\
\text { correlação }\end{array}$ & Positiva & Negativa \\
\hline Perfeita & & \\
\hline Muito forte & & \\
\hline Forte & & \\
\hline Moderada & & \\
\hline Fraca & & \\
\hline Nula & & \\
\hline
\end{tabular}

Legenda: Floresta Estacional Semidecidual (FES); reflorestamento (RF); vegetação de área úmida (VAU); lavoura temporária (LT); silvicultura (SC); pasto (P); pasto sujo (PS); área de terraço e planície fluvial (ATPF); fundo de vale plano (FVP); fundo de vale em "v" (FVV); canal com solapamento das margens (CSM); marcas que indicam erosão laminar (ML); sulco (S); ravina (R); voçoroca (V); ruptura topográfica abrupta (RTA); ruptura topográfica abrupta com afloramento de água (RTA-A); canal antropogênico (CA); açude (A); bacias de contenção (BC) e terraços agrícolas (TA); feições erosivas obliteradas (FO)

Fonte: Elaboração dos autores, 2019

A Floresta Estacional Semidecidual, reduzida ao longo do período analisado, apresentou correlação negativa com as formas erosivas, sendo a correlação perfeita com as marcas que indicam erosão laminar, muito forte com o voçorocamento e forte com sulcos e ravinas. Essa correlação é em parte justificada pelo aumento de feições erosivas em áreas que antes eram ocupadas por vegetação original, como demonstra a figura 6 , contudo também deve-se ao fato de ocorrer uma diminuição progressida dessa vegetação e aumento das feições erosivas, fato que não pode ser compreendido como o surgimento de erosão somente nos locais onde ocorreu o desmatamento. $\mathrm{O}$ aumento das feições erosivas ocorre em praticamente toda a área estudada, em diversas condições de uso da terra.

O pasto, cobertura predominante na área estudada, apresentou perfeita correlação positiva com as marcas que indicam erosão laminar, forte positiva com sulcos, moderada positiva com as ravinas e muito forte positiva com as voçorocas.

Com as lavouras temporárias a correlação foi negativa, sendo forte com a voçoroca e muito forte com as marcas que indicam erosão laminar. Em campo registraram-se marcas que indicaram ação erosiva laminar e formação de sulcos em áreas de cana-de-açúcar. Essas feições não foram possíveis de mapear devido às correções constantes dos terraços agrícolas (Figura 8). 
Figura 8 - Marcas de erosão laminar e sulcos em solos sob cana-de-açúcar (2013). Fotografias após evento chuvoso.

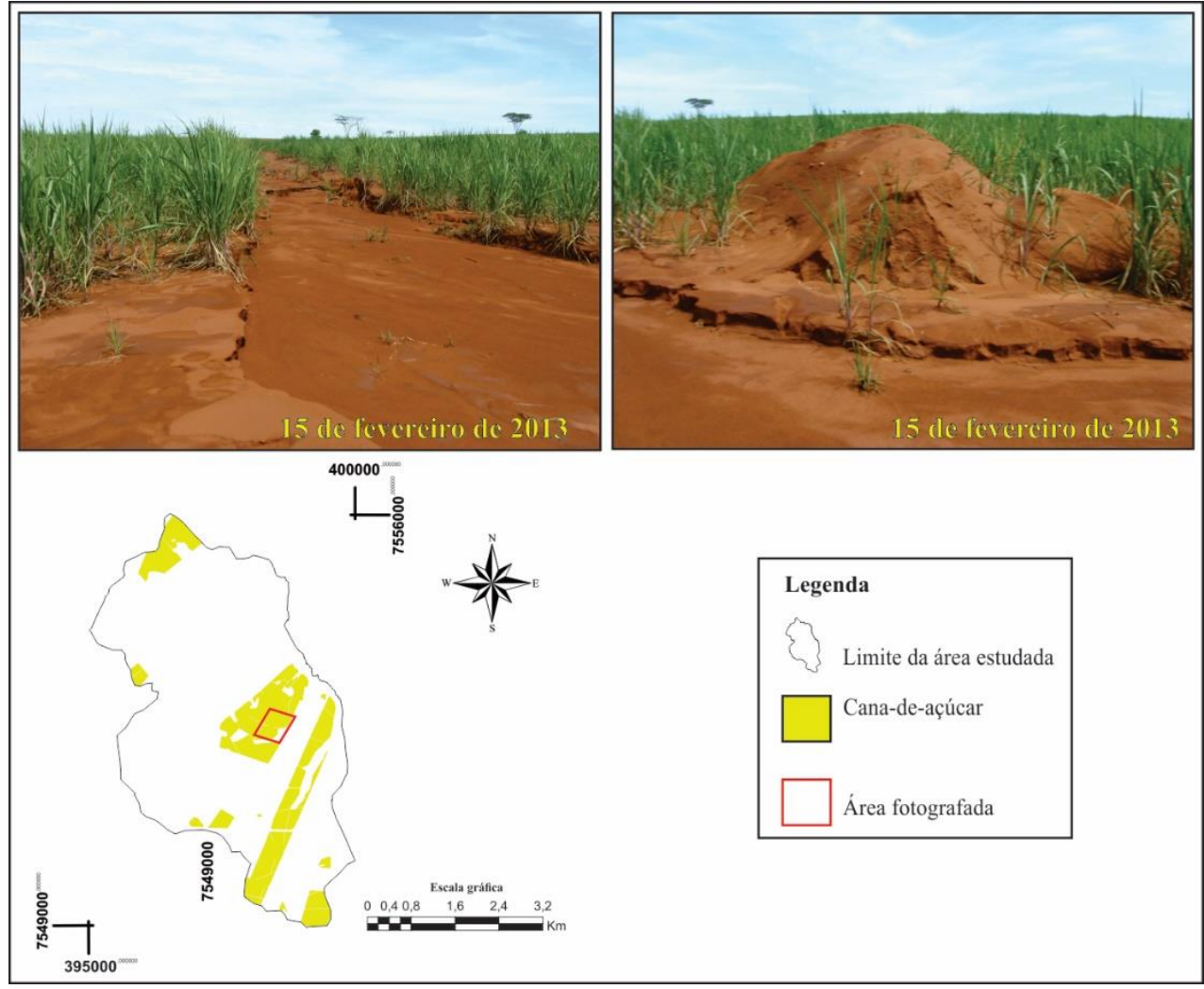

Fonte: Elaboração dos autores, 2019.

A análise realizada permitiu constatar que o desenvolvimento dos processos erosivos ocorre de maneira conjunta, de modo que as feições erosivas apresentaram correlação positiva entre si: as marcas que indicam erosão laminar tiveram forte correlação com sulcos e ravinas e perfeita correlação com as voçorocas. Os sulcos exibiram correlação muito forte com ravinas e voçorocas, sendo forte a correlação entre as ravinas e as voçorocas. Essas correlações indicam que a evolução de uma forma erosiva se encontra interligada aos demais processos que ocorrem na mesma subbacia (Figura 9).

Como exemplificado na Figura 9, as formas erosivas encontram-se conectadas. No ano de 1963, diversos sulcos direcionavam-se para a concavidade. Nesta concavidade, em 1979 registrou-se a formação de ravinamento, aumentando o número de sulcos e marcas que indicam erosão laminar nas demais vertentes. No ano de 1997, a mencionada ravina desenvolveu-se para voçoroca, e outras ravinas surgiram em suas margens, nas quais convergem sulcos dos setores mais elevados. Nos anos de 2011 e 2016, essa dinâmica se intensificou, com as ravinas evoluindo para montante e dezenas surgindo nas baixas vertentes, com um maior número de sulcos e marcas que indicam erosão laminar. Em relação às técnicas conservacionistas, a correlação apontou para a baixa eficiência dos terraços e bacias de contenção na conservação dos solos, uma vez que apresentam correlação positiva com todas as formas erosivas: muito forte com os sulcos; perfeita com as ravinas; e forte com as voçorocas.

Constatou-se que as mudanças nos fundos de vale estão também relacionadas aos processos nas vertentes e às técnicas conservacionistas, como registrado na Figura 4. As formas erosivas apresentaram correlação negativa com os fundos de vale em "v" e plano e positiva de muito forte à perfeita com as áreas de terraço e planície fluvial. Os processos erosivos nas vertentes aumentam o fluxo de água e sedimentos para os fundos de vale, de modo a ampliarem as áreas de sedimentação, resultando na correlação positiva com as áreas de terraço e planície fluvial, e redução dos canais com fundo em "v" e plano, nos quais a correlação foi negativa com todas as formas erosivas (Figura 10) 
Figura 9 - Evolução das formas erosivas na subbacia W, atingida por voçorocamento a partir de 1997.

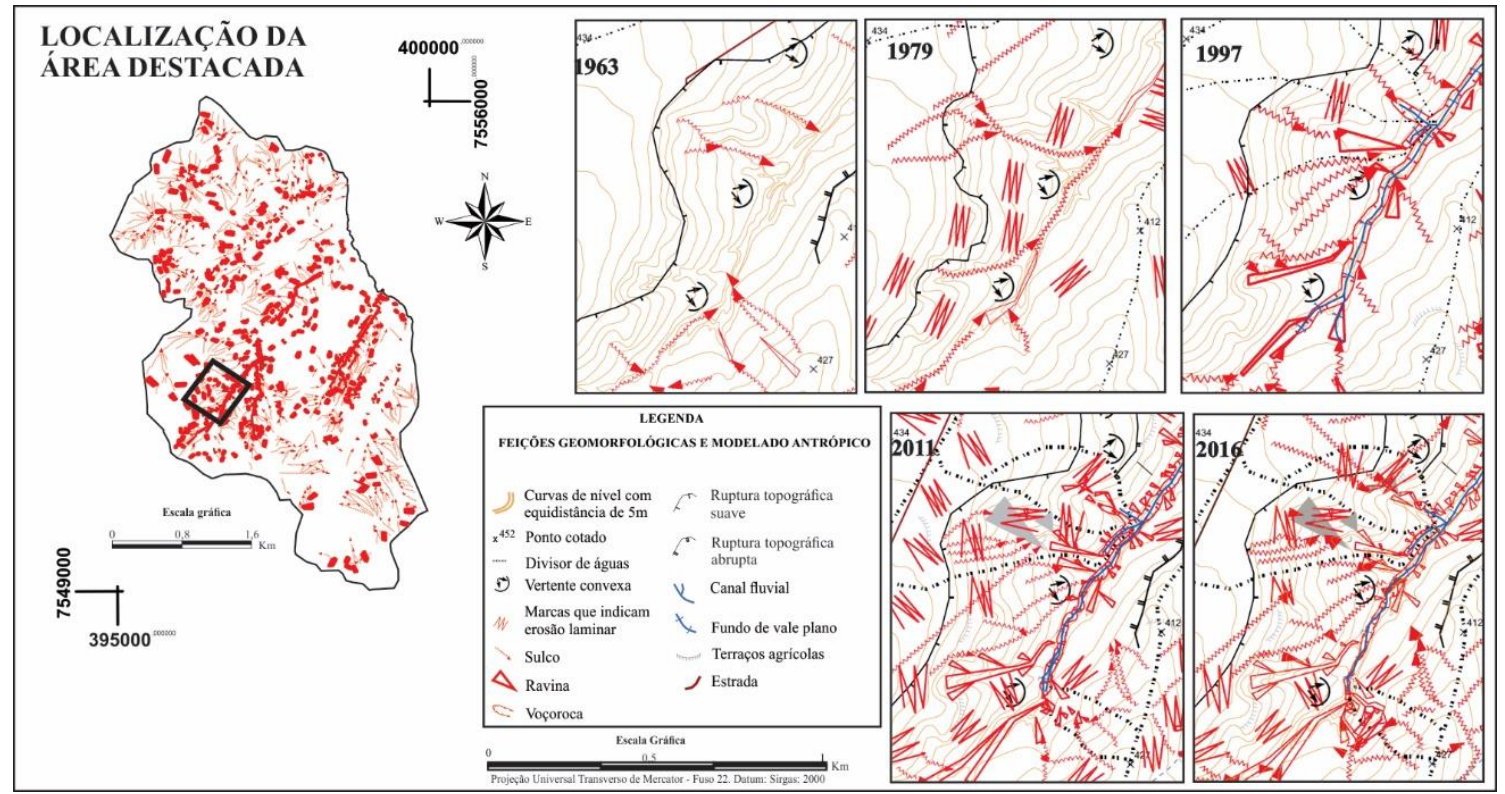

Fonte: Elaboração dos autores, 2019.

Figura 10 - Processos erosivos nas vertentes com consequente solapamento das margens e formação de áreas de terraço e planície fluvial em canal de fundo plano

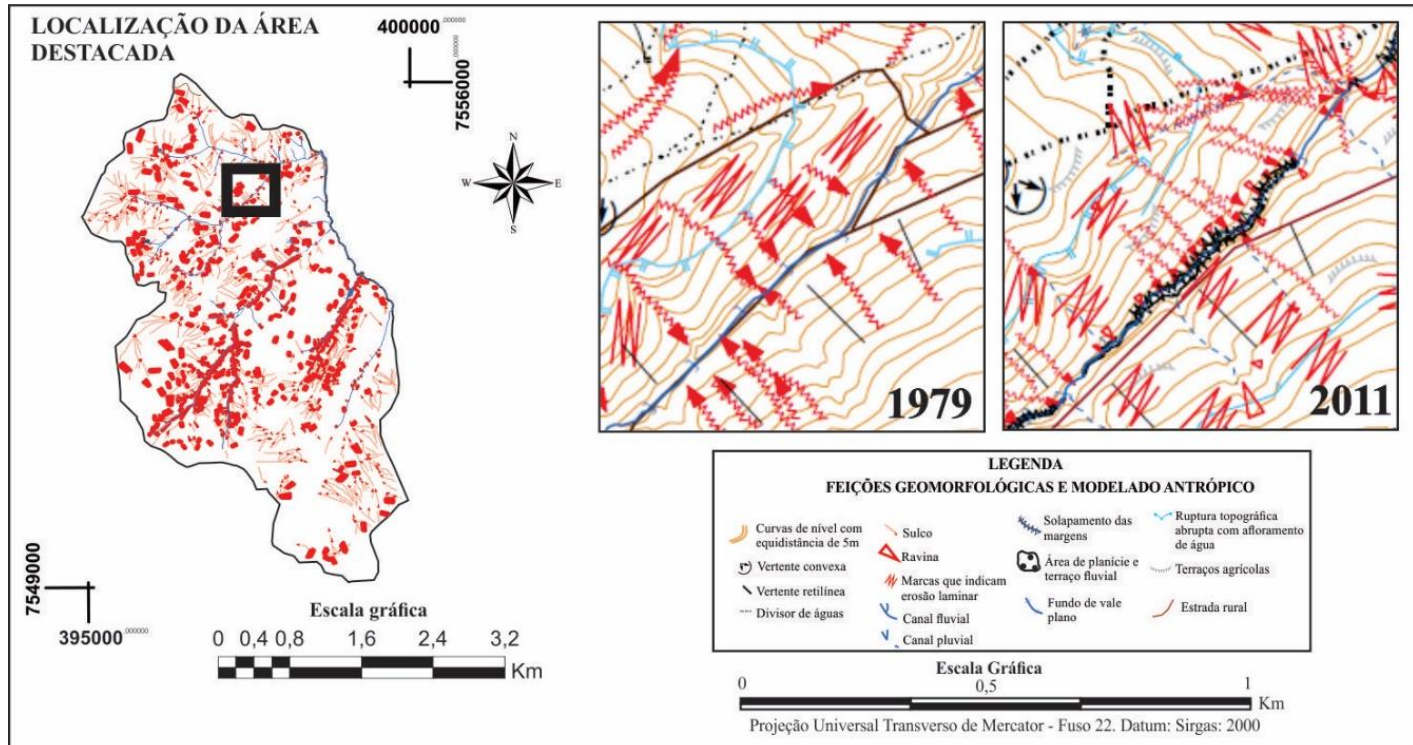

Fonte: Elaboração dos autores, 2019.

Como destacado na Figura 10, o aumento das feições erosivas entre 1979 e 2011 proporcionou maior sedimentação dos fundos de vale, ampliando a área de deposição. Nesse período também se verificou que essa sedimentação excessiva criou alterações no curso do canal principal, com a presença de solapamento das margens. Este processo, ao atingir a base da vertente, proporcionou seu colapso, de maneira a derivar em dezenas de pequenas ravinas que se desenvolvem por erosão remontante; essa relação foi também apontada por Stein, Ponçano e Saad (2003) em estudo realizado na bacia do rio Santo Anastácio e do ribeirão Areia Dourada.

Os afloramentos de água nas rupturas topográficas, quando verificados juntos aos mapeamentos geomorfológicos, sobretudo de 1979 e 1997, deram origem a pequenos canais fluviais com fundo de vale em "v" a jusante. Esses canais, em 2011, tiveram seu comprimento reduzido pela construção de açudes, que limitaram o fluxo até a montante da barragem, não verificando escoamento a jusante (Figura 11). 
Figura 11 - Tributários do canal principal antes (1997) e após (2011 e 2016) barramento e formação de açude. (1) Ausência de escoamento superficial de água a jusante da nascente no setor NW; (2) ausência de escoamento superficial de água a jusante da nascente a W.

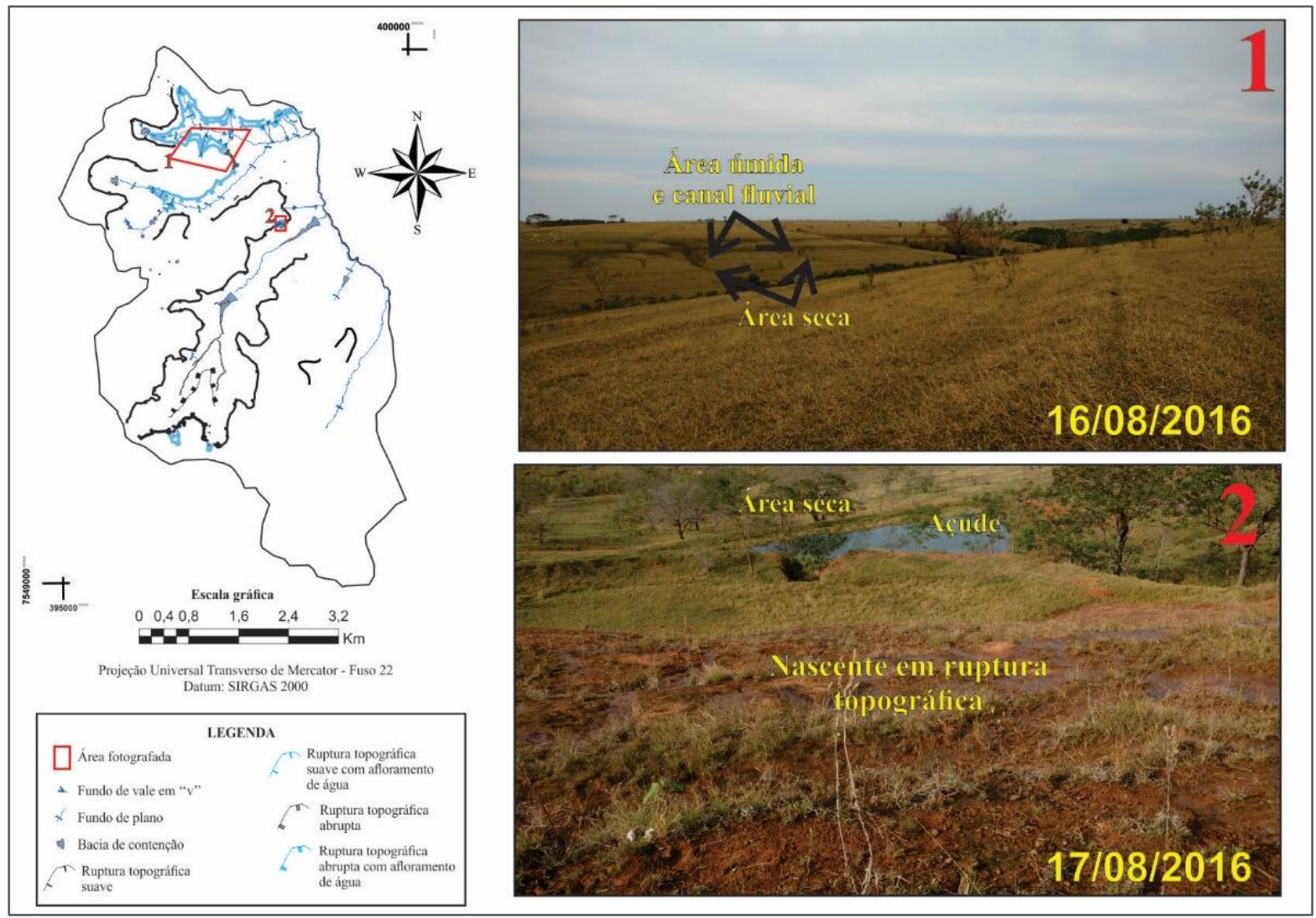

Fonte: Elaboração dos autores, 2019.

Desse modo, a correlação negativa entre as rupturas topográficas abruptas com o afloramento de água e os fundos de vale em "v" não se sustenta quando avaliada conjuntamente com os mapeamentos e registros de campo, uma vez que as técnicas conservacionistas e os açudes apresentaram-se como variáveis de maior interferência nos fundos de vale. $\mathrm{O}$ aumento da infiltração proporcionada pelas técnicas conservacionistas e o barramento dos cursos d'água, transformaram os canais com fundo em "v" em pluviais, como exemplificado na Figura 8.

No caso da bacia com maior processo de voçorocamento (Figura 12), verificou-se que após o barramento do fluxo de água com a formação de um açude, obliterações e bacias de contenção, ocorreram modificações na dinâmica erosiva, alterando a localização e o desenvolvimento das ravinas em relação aos anos anteriores, de modo a registrar o surgimento de dezenas destas a partir da baixa vertente em 2011.

Outra voçoroca mapeada, no setor sudeste da área estudada, tem seu escoamento direcionado a uma antiga estrada rural (Figura 13). Nesta área, até 2011, o fluxo de água na base da erosão era absorvido pelo solo, enquanto em 2016 o escoamento superficial passou a atingir o canal fluvial, também afetado por processo de voçorocamento, a jusante da barragem. Esse aumento do fluxo de água na base da erosão se deve a maior infiltração de água proporcionado pelas bacias de contenção e terraços agrícolas estabelecidos nas vertentes. 
Figura 12 - Mudanças no padrão da formação e desenvolvimento de ravinas após a barragem do fluxo de água da voçoroca.

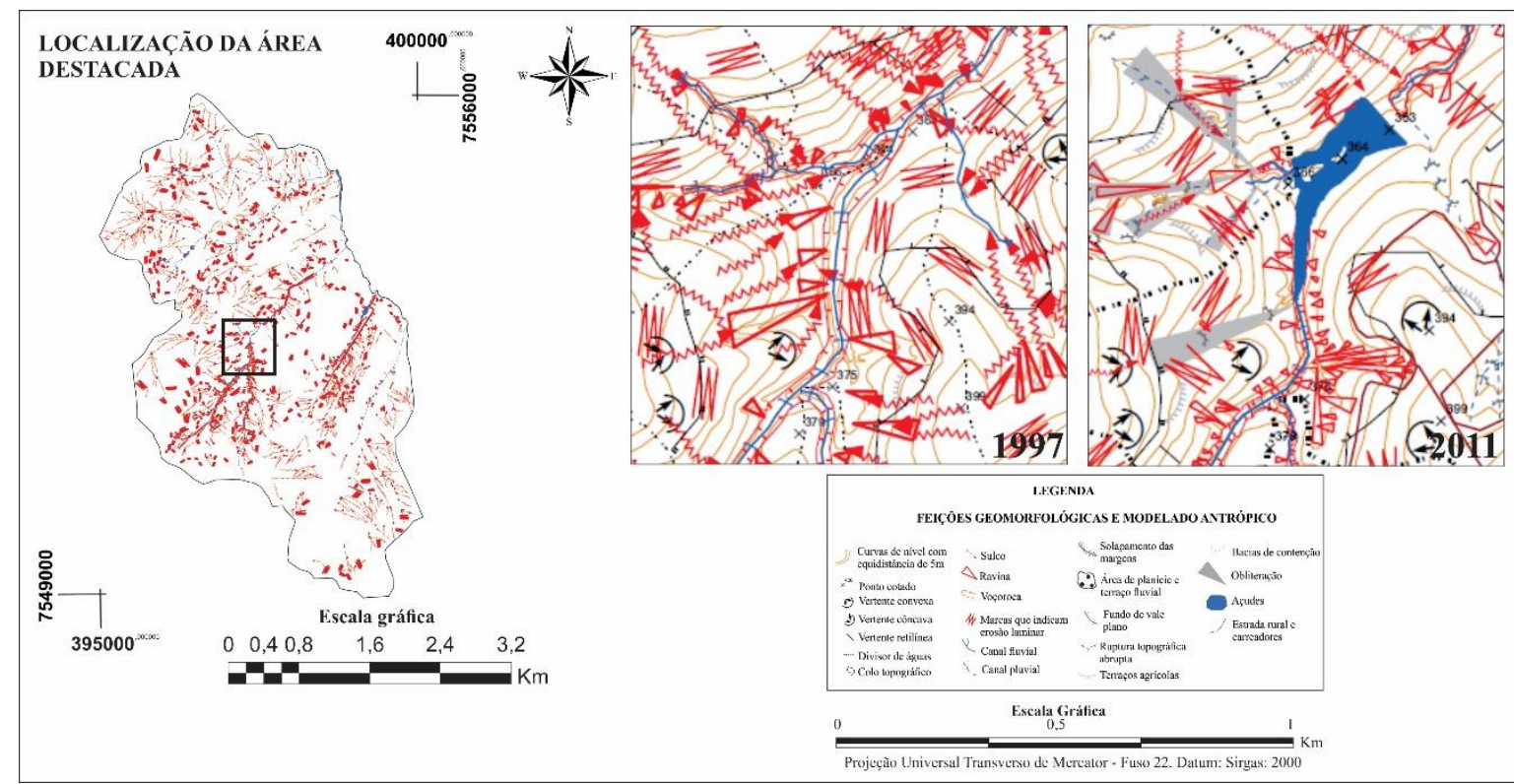

Fonte: Elaboração dos autores, 2019.

Figura 13 - Influência dos terraços agrícolas no fluxo de água no canal antropogênico resultado do processo de voçorocamento que atinge a estrada rural. (1) Escoamento superficial de água na base da voçoroca em 2011; (2) Escoamento superficial de água na base da voçoroca em 2016.

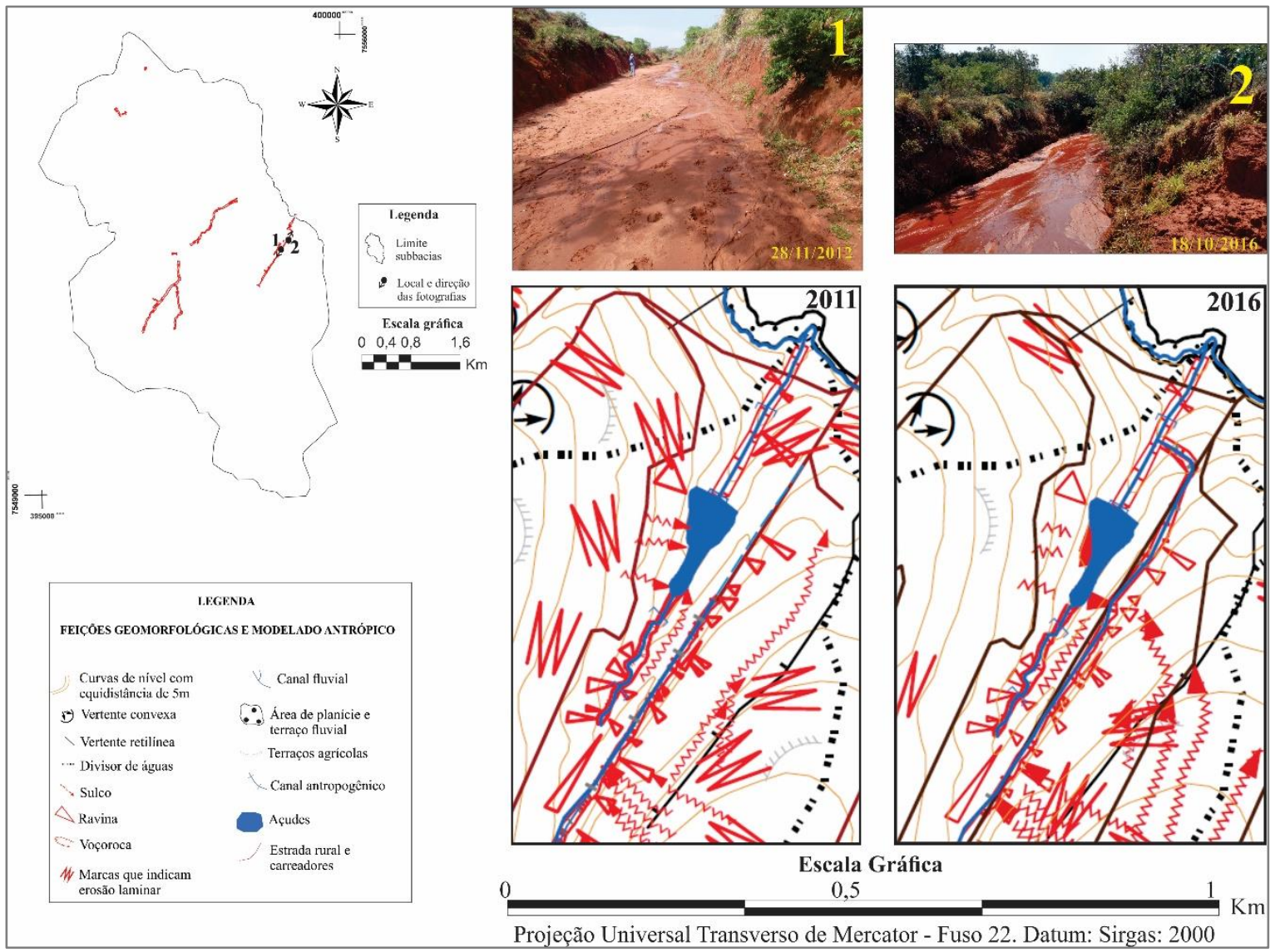

Fonte: Elaboração dos autores, 2019. 
No setor mais ao norte da área estudada (Figura 14), os terraços agrícolas proporcionaram volume maior de afloramento de água nas rupturas topográficas abruptas, em setores de pastoreio excessivo dos terrenos.
Nessas circunstâncias, de uso excessivo e maior fluxo de água que afloram das rupturas, registrou-se o desenvolvimento de uma voçoroca no ano de 2011 e, posteriormente, outras duas em 2016.

Figura 14 - Desenvolvimento de voçorocas a jusante de rupturas topográficas com afloramento de água. Fotografias 1, 2 e 3: voçorocas no setor NNW da área estudada.

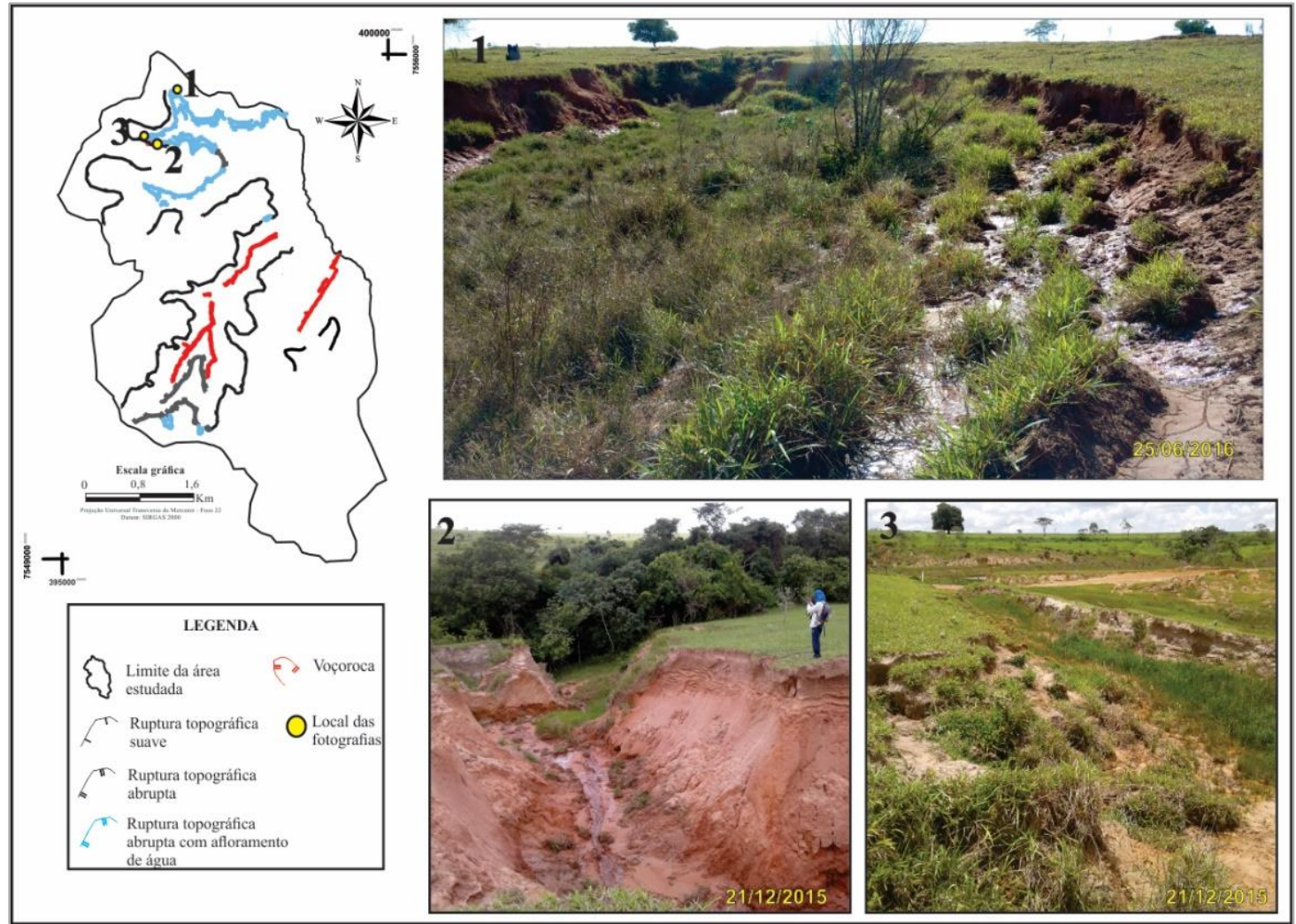

Fonte: Elaboração dos autores, 2019.

De forma geral, é possível afirmar que os dados demonstraram a existência de um uso intenso em praticamente todas as vertentes, em detrimento de reflorestamentos e culturas que ofereçam melhorias na estrutura do solo arenoso e maior proteção a ação erosiva das chuvas, favorecendo a formação e desenvolvimento de processos erosivos, de maneira a prognosticar, que se as condições atuais se mantiverem, a tendência é ao aumento dos fenômenos erosivos e a contínua perda de solo, mesmo quando se faz o uso de distintas técnicas conservacionistas.

\section{CONSIDERAÇÕES FINAIS}

Através das técnicas utilizadas pode-se identificar a dinâmica erosiva- deposicional, de modo a constatar a conexão entre as formas erosivas nos diversos compartimentos topográficos da área estudada. Estas proporcionaram alterações nos fundos de vale, com solapamento das margens fluviais, promovendo o colapso das baixas vertentes e originando diversas ravinas. Estas ravinas aumentam o fluxo de água e sedimentos nos fundos de vale, estabelecendo um ciclo erosãoassoreamento que se retroalimenta.

As pastagens apresentaram-se como catalisadoras de muitos dos processos lineares identificados. $\mathrm{O}$ pisoteio excessivo do gado gerou a compactação da camada superficial, por onde se desenvolvem sulcos, que se inserem na dinâmica erosiva supramencionada.

As técnicas conservacionistas contribuíram com o desenvolvimento dos processos erosivos através de recargas do lençol, que, associados ao uso intenso dos solos, favoreceram os processos de subsuperfície característicos das voçorocas, ao mesmo tempo em que não reduziram os processos de superfície. Quanto as barragens, em canais com voçorocamento, essas estabeleceram alterações na forma de 
desenvolvimento da erosão, com surgimento de dezenas de pequenas ravinas em toda baixa vertente, as quais não ficaram mais restritas às concavidades como registrado em períodos anteriores à barragem.

De maneira geral, através da cartografia retrospectiva e do Coeficiente de Correlação de Pearson pode-se levantar hipóteses sobre a influência do uso e cobertura superficial da terra nas mudanças das feições geomorfológicas identificadas na área estudada ao longo de 53 anos. Tais constatações podem contribuir com o entendimento da dinâmica erosiva, questão relevante para uma possível recuperação das subbacias do ribeirão Areia Dourada.

\section{AGRADECIMENTOS}

À Coordenação de Aperfeiçoamento de Pessoal de Nível Superior (CAPES) pelo financiamento do primeiro mês de pesquisa: de abril a maio de 2015 e à Fundação de Amparo à Pesquisa do Estado de São Paulo (FAPESP) pelo financiamento do projeto de doutorado, processo n. ${ }^{\circ}$ 2015/00875-2, de maio de 2015 a abril de 2018.

Aos parecistas pelas contribuições na melhora deste artigo.

\section{REFERÊNCIAS}

ABDON, M. M. Os impactos ambientais no meio físico - erosão e assoreamento na bacia hidrográfica do Rio Taquari, MS, em decorrência da pecuária. Tese (Doutorado em Ciências da Engenharia Ambiental). Escola de Engenharia de São Carlos da Universidade de São Paulo, 2004. 319p.

BERTONI, J; LOM BARDI-NETO, F. Conservação do solo. São Paulo: Ícone, 1990.

BORGES, P. A evolução dos processos erosivos na bacia hidrográfica do ribeirão Alam Grei (SP): uma contribuição ao planejamento ambiental. Dissertação (Mestrado em Geografia - Organização do Espaço). Instituto de Geociência e Ciências Exatas, Universidade Estadual Paulista, 2009.

CARVALHO, W. A. (coord.). Levantamento semidetalhado dos solos da bacia do rio Santo Anastácio-SP. Presidente Prudente, São Paulo: FCT- UNESP, 1997. v.1 e v.2.
CHARLTON, R. Fundamental of fluvial geomorphology. Routledge Taylor \& Francis Group: London and New York, 2008.

DEPARTAMENTO DE ÁGUAS E ENERGIA ELÉTRICA (DAEE); INSTITUTO DE PESQUISAS TECNOLÓGICAS (IPT). Controle de erosão: bases conceituais e técnicas; diretrizes para o planejamento urbano e regional; orientações para o controle de boçorocas urbanas. São Paulo: DAEE/IPT, 1989.

FRANCISCO, A. B. A erosão dos solos no extremo oeste paulista e seus impactos no campo e na cidade. Revista GEOMAE, Campo Mourão, v.2, n.2, p.57-68, 2011.

FIGUEIREDO FILHO, D. B.; SILVA JUNIOR, J. A. Desvendando os Mistérios do Coeficiente de Correlação de Pearson ${ }^{\circledR}$. Revista Política Hoje, Vol. 18, n.1, p. 115-146, 2009.

FOOKES, P. G.; LEE, E. M.; GRIFFITHS, J. S.

Engineering geomorphology: theory and practice. Dunbeath: Whittles Publishing, 2007.

INSTITUTO BRASILEIRO DE GEOGRAFIA E ESTATÍSTICA (IBGE). Manual Técnico de Uso da Terra. $3^{a}$ edição. Rio de Janeiro: IBGE, 2006.

KARMAN, I. Ciclo da água: água subterrânea e sua ação geológica. In: TEIXEIRA, W.; TOLEDO, M. C. M.; FAIRCHILD, T. R.; TAIOLI, F (org.). Decifrando a Terra. São Paulo: Companhia Editora Nacional, 2008. 557p.

LAL, R. Soil erosion in the tropics: principles and management. New York: McGraw- Hill, 1990.

LUZ, R.; RODRIGUES, C. Anthropogenic changes urbanised hidromorphological systems in a humid tropical environment River Pinheiros, São Paulo, Brasil. Zeitschrift fur Geomorphologie. Supplementband, v. 59, p. 109, 2015. http://dx.doi.org/10.1127/zfg_suppl/2015/S59207

NIR, D. Man, a geomorphological agent: an Introduction to Anthropic Geomorphology. Keter Piblishing House: Jeresalem, 1983.

PASCHOLA, L. G. Estudo dos efeitos da criação de morfologias antropogênicas em áreas de mineração. Tese (Mestrado em Geografia - Organização do Espaço). Instituto de Geociência e Ciências Exatas, Universidade Estadual Paulista, 2014, p.?

PREFEITURA DE MARABÁ PAULISTA. Informações sobre a história da cidade. Disponível em: $<$ https://marabapaulista.sp.gov.br/cidade>. Acesso em 08 de dezembro de 2019. 
QUARESMA, C. C. Reativação da rede de drenagem e processos erosivos na bacia do rio Santo Anastácio - SP/BRASIL: contribuições à geomorfologia antrópica e ao entendimento das organizações espaciais. Tese (Doutorado em Geografia), Universidade Estadual de Campinas.

RODRIGUES, J. O. N.; PERUSI, M. C.; PETERLINI, G. H. C.; TIEZZI, R. O.; PISANI, R. J.; SANTANA, E. L. R. Variações texturais dos Latossolos Vermelhos do assentamento rural Antonio Conselheiro - Mirante do Paranapanema (SP). Geografia em Atos, n.6, v.1, Presidente Prudente, 2006.

SALOMÃO, F. X. T. Controle e prevenção dos processos erosivos. In: GUERRA, A. J. T.; SILVA, A. S.; BOTELHO, R. G. M. (Org.). Erosão e conservação dos solos: conceitos, temas e aplicações. $8^{a}$ edição. Rio de Janeiro: Bertrand Brasil, 2012.

SIMON, A. L. H. A influência de reservatórios hidrelétricos sobre a morfohidrografia na baixa bacia do rio Piracicaba SP: contribuições ao estudo da Geomorfologia Antropogênica. Tese (Doutoramento Geografia - Organização do Espaço), Instituto de Geociência e Ciências Extadas, Universidade Estadual Paulista. São Paulo, 2010

SOIL SURVEY STAFF. Soil Survey Manual. USDA: Soil Conservation Service,Agricultural Handbook. $N^{0}$ 18, U. S. Gov. Print: Office, Wahsington, D. C. 1993.

SOUZA, T. A.; REGINA, C. O. Avaliação da potencialidade de imagens tridimensionais em meio digital para o mapeamento geomorfológico. REVISTA GEONORTE. Edição especial, v.2, n.4, p.1348- 1355, 2012.

STEIN, D. P.; PONÇANO, W. L.; SAAD, A. R. Erosão na bacia do Rio Santo Anastácio, Oeste do estado de São Paulo, Brasil. Revista Geociências. v.22, n.2, p.143-161, 2003.

TRICART, J. Principes et méthodes de la géomorphologie. Paris: Masson, 1965, 496p.

VERSTAPPEN, H. T.; ZUIDAM, R. A. System of geomorphological survey. Netherlands, Manual ITC Textbook, Vol. VII, Chapter VII, 1975.

WENDLING, B.; MENDONÇA, E.S.; NEVES, J. C. L. Carbono orgânico e estabilidade de agregados de um Latossolo Vermelho sob diferentes manejos. Pesquisa Agropecuária Brasileira. Brasília, v.40, n.5, p.489-494, 2005.

ZANATTA, F. A. S.; LUPINACCI, C. M.; BOIN, M.N. Avaliação dos processos erosivos no Planalto Ocidental Paulista: um estudo de caso em busca das interações especiais. Revista
Brasileira de Geomorfologia, v.18, $\mathrm{n}^{\circ}$ 4, p. 767-782, 2017a. http://dx.doi.org/10.20502/rbg.v18i4.1029

ZANATTA, F. A. S.; LUPINACCI, C. M.; BOIN, M.N. O uso de anaglifos na identificação de feições erosivas: estudo de caso em área rural degradada. In: BOIN, M.N.; MARTINS, P. C. S.; MIRANTE, M. H. P. (Org.). Geotecnologias aplicadas às questões ambientais. Tupã (SP), ed. ANAP, $1^{\mathrm{a}}$ ed., vol.1, p.31-53, $2017 \mathrm{~b}$. 